\title{
Mutations at the accommodation gate of the ribosome impair RF2-dependent translation termination
}

\author{
DMITRY E. BURAKOVSKY, ${ }^{1,2,3}$ PETR V. SERGIEV,${ }^{1,2}$ MARIA A. STEBLYANKO,${ }^{1,2,6}$ ANDRIY V. KUBARENKO, ${ }^{4,7}$ \\ ANDREY L. KONEVEGA, ${ }^{3,5}$ ALEXEY A. BOGDANOV, ${ }^{1,2}$ MARINA V. RODNINA, ${ }^{3,4}$ and OLGA A. DONTSOVA ${ }^{1,2}$ \\ ${ }^{1}$ Department of Chemistry, Moscow State University, Moscow, 119899, Russia \\ ${ }^{2}$ A.N. Belozersky Institute of Physico-Chemical Biology, Moscow State University, Moscow, 119899, Russia \\ ${ }^{3}$ Department of Physical Biochemistry, Max Planck Institute for Biophysical Chemistry, 37077 Göttingen, Germany \\ ${ }^{4}$ Institute of Physical Biochemistry, University of Witten/Herdecke, 58448 Witten, Germany \\ ${ }^{5}$ Petersburg Nuclear Physics Institute, 188300 Gatchina, Russia
}

\begin{abstract}
During protein synthesis, aminoacyl-tRNA (aa-tRNA) and release factors 1 and 2 (RF1 and RF2) have to bind at the catalytic center of the ribosome on the $50 \mathrm{~S}$ subunit where they take part in peptide bond formation or peptidyl-tRNA hydrolysis, respectively. Computer simulations of aa-tRNA movement into the catalytic site (accommodation) suggested that three nucleotides of 23S rRNA, U2492, C2556, and C2573, form a "gate" at which aa-tRNA movement into the A site is retarded. Here we examined the role of nucleotides C2573 of 235 rRNA, a part of the putative accommodation gate, and of the neighboring A2572 for aa-tRNA binding followed by peptide bond formation and for the RF2-dependent peptide release. Mutations at the two positions did not affect aa-tRNA accommodation, peptide bond formation, or the fidelity of aa-tRNA selection, but impaired RF2-catalyzed peptide release. The data suggest that the ribosome is a robust machine that allows rapid aa-tRNA accommodation despite the defects at the accommodation gate. In comparison, peptide release by RF2 appears more sensitive to these mutations, due to slower accommodation of the factor or effects on RF2 positioning in the A site.
\end{abstract}

Keywords: translation; ribosome; decoding; accommodation; release factor

\section{INTRODUCTION}

The catalytic site of the bacterial ribosome-the peptidyl transferase center-is located in domain V of $23 \mathrm{~S}$ rRNA in the large ribosomal subunit (50S). During peptide bond formation, the $\alpha$-amino group of the A-site aa-tRNA attacks the carbonyl carbon of the P-site peptidyl-tRNA (pepttRNA) to produce a new, 1-amino acid-longer pept-tRNA in the $\mathrm{A}$ site and a deacylated tRNA in the $\mathrm{P}$ site. The second enzymatic activity associated with the peptidyl transferase center is the hydrolytic cleavage of the ester bond in pept-tRNA during termination of protein synthe-

Present addresses: ${ }^{6}$ Kimmel Cancer Center, Thomas Jefferson University, 233 South 10th Street, BLSB, 706, Philadelphia, Pennsylvania 19107, USA; ${ }^{7}$ German Cancer Research Center (DKFZ), Im Neuenheimer Feld 580, 69120 Heidelberg, Germany.

Reprint requests to: Olga A. Dontsova, Department of Chemistry, Moscow State University, Moscow, 119899, Russia; e-mail: dontsova@ libro.genebee.msu.ru; fax: +7-495-939-3181; or Marina V. Rodnina, Max Planck Institute of Biophysical Chemistry, 37077 Göttingen, Germany; e-mail: rodnina@mpibpc.mpg.de; fax: +49-551-201-2905.

Article published online ahead of print. Article and publication date are at http://www.rnajournal.org/cgi/doi/10.1261/rna.2185710. sis. Peptide bond formation (the aminolysis reaction) is an intrinsic activity of the ribosome that requires that the $3^{\prime}$-ends of the two tRNAs are correctly positioned in the A and $\mathrm{P}$ sites of the peptidyl transferase center, but does not involve an auxiliary factor. In contrast, peptide release from pept-tRNA is promoted by release factors, RF1 or RF2, which upon recognition of a termination codon in the $30 \mathrm{~S}$ decoding site reach into the active site on the $50 \mathrm{~S}$ subunit. In both aminolysis and hydrolysis reactions, one substrate is pept-tRNA positioned in the $\mathrm{P}$ site of the ribosome in the course of the preceding round of elongation. The respective reaction partner in the A site, aminoacyl-tRNA or RF1/2, has to bind, recognize the A-site codon, and accommodate in a way poised for the reaction. Because the peptidyl transferase center is located in a cleft at the interface side of the 50S subunit, this requires that the reactive domains, the 3 '-end of aa-tRNA or the tip of domain 3 of RF1/2, move $\sim 70 \AA$ from the tRNA/factor entry site into the peptidyl transferase center of the ribosome in a process that has been termed accommodation of aa-tRNA.

The mechanism of the accommodation is not known in detail. Computer simulation of the aa-tRNA movement from 
its $\mathrm{A} / \mathrm{T}$ position, where the $3^{\prime}$-end of the aa-tRNA is attached to EF-Tu at the periphery of the ribosome, into the A/A position with the 3 '-end positioned in the peptidyl transferase center suggested a step-wise movement through a corridor of conserved rRNA bases, which interact with the tRNA during the accommodation movement (Sanbonmatsu et al. 2005). The final accommodation of aa-tRNA in the A site of the peptidyl transferase center appears to be impeded by the interaction between the $3^{\prime}$-CCA end of aatRNA and the A-loop (helix 92) of $23 \mathrm{~S}$ rRNA, in particular, the universally conserved bases U2492, C2556, and C2573, which act as a gate, causing the acceptor stem to pause before allowing entrance into the peptidyl transferase center (Sanbonmatsu et al. 2005). According to that simulation, the acceptor end of the aa-tRNA pauses upon interaction with U2492 and C2556 of 23S rRNA until the U2492-C2556 gate opens allowing the CCA end to proceed through. The CCA end then immediately interacts with C2573, causing it to pause for a second time (Fig. 1; Sanbonmatsu et al. 2005). Previous mutagenesis studies (O'Connor and Dahlberg 1995) indicated that substitutions of U2492 and U2555 affect the fidelity of translation, supporting the view that the accommodation gate may attenuate aa-tRNA binding. These results prompted us to further test the role of the $23 \mathrm{~S}$ rRNA bases forming the gate by introducing mutations at critical positions that have not been previously studied by mutagenesis.

The base of C2573 of 23S rRNA is oriented toward the accommodation corridor through which aa-tRNA passes on its way into the A site on the 50S subunit. Substitution of C2573 for a larger purine base should create an obstacle for the movement and thus decrease the accommodation rate. In contrast, deletion of C2573 is expected to promote accommodation by facilitating the access of the tRNA into the A site. Also nucleotide A2572, although it is not a part of the accommodation gate, is of interest as a target for mutagenesis. A2572 is adjacent to C2573, but is oriented away from the accommodation gate due to the sharp kink
A

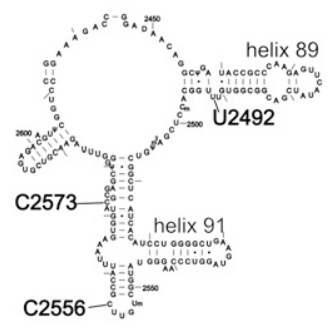

B

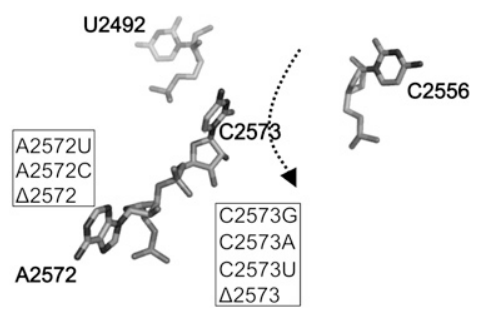

FIGURE 1. Positions of 23S rRNA bases U2492, C2556, and C2573 suggested to form the aa-tRNA accommodation gate (Sanbonmatsu et al. 2005) in the secondary $(A)$ and tertiary $(B)$ structures of $23 \mathrm{~S}$ rRNA. The arrow indicates the direction of movement of the 3 '-end of aa-tRNA. Substitutions of nucleotides studied in this work are listed in boxes in $B$. of the backbone between the two nucleotides. There is evidence suggesting that A2572 is involved in conformational changes in the vicinity of the peptidyl transferase center. A2572 becomes more accessible to chemical modification by dimethyl sulfate (DMS) when the $\mathrm{pH}$ is lowered (which impairs peptide bond formation) (Katunin et al. 2002) or upon inactivation of the $50 \mathrm{~S}$ subunits in a low-salt buffer (Zamir et al. 1974). The reactivity of A2572 toward DMS also increases as a consequence of various unrelated base exchanges, such as A960C (Sergiev et al. 2000), A2451U (Mycobacterium smegmatis) (Beringer et al. 2005), A2531C and A2531U (Chan et al. 2006), or the K63E mutation of protein L4 (Gregory and Dahlberg 1999). In the two crystal forms of the Escherichia coli 70 S ribosome (Borovinskaya et al. 2007), A2572 occupies two positions that differ in their orientation toward ribosomal protein L3. In the structure where A2572 is involved in the stacking interaction with Gln150 of protein L3, the latter residue is methylated. Residue mGln 150 of protein L3 in E. coli corresponds to Trp255 of protein L3 in yeast ribosomes, for which various A-site-related mutant phenotypes have been observed (Meskauskas and Dinman 2007). These observations may suggest that A2572 is involved in long-range communications within the large ribosomal subunit, which might affect the size of the gate and hence the accommodation efficiency, or even aa-tRNA selection directly. Accommodation of RF1/2 in the A site may also require movement through the accommodation corridor; however, this has not been tested so far. Here, we have studied the effects of mutations of $23 \mathrm{~S}$ rRNA residues 2573 and 2572 on ribosome function, in particular, on aa-tRNA accommodation during peptide elongation and RF2-dependent termination.

\section{RESULTS AND DISCUSSION}

\section{Site-directed mutagenesis and effects of mutations in vivo}

Using site-directed mutagenesis we changed the base of A2572 to a pyrimidine ( $\mathrm{U}$ or $\mathrm{C}$ ) or deleted the nucleotide. Nucleotide C2573 was replaced by three other nucleotides or deleted. The plasmid carrying the mutated rRNA operon was introduced by plasmid exchange into an E. coli strain that lacked all seven chromosomal rRNA operons (Asai et al. 1999). The strains were viable and did not show significant impairment in cell growth, except for the two deletion mutations, $\Delta 2572$ and $\Delta 2573$, both of which were lethal.

Mutations that change the efficiency of aa-tRNA accommodation in the A site were expected to have an effect on translation fidelity. We checked the effect of the mutations on the frequency of translation errors in vivo with the help of reporter plasmids containing mutant variants of the lac $Z$ gene (Cupples and Miller 1989; O'Connor and Dahlberg 1993). In this system, active $\beta$-galactosidase could only be synthesized as a result of various translational errors, such 
as stop-codon readthrough, \pm 1 frameshifting, or codon misreading. Whereas the mutation C2573A slightly decreased the misreading frequency (Fig. 2), the effects of other mutations on misreading were insignificant. The efficiency of frameshifting or stop-codon readthrough was not affected significantly by any of the mutations (data not shown). The lack of misreading and frameshifting effects suggested that the mutations (except C2573A and the two deletion mutations) had no significant influence on the rates of aatRNA selection.

\section{Effects of mutations on 235 rRNA structure}

To test the effects of mutations on the structure of $23 \mathrm{~S}$ rRNA and on elemental steps of translation in vitro, mutant as well as wild-type ribosomes from the same genetic background were prepared. The mutants were selected according to their expected effect on the aa-tRNA accommodation rate: $\mathrm{C} 2573 \mathrm{~A}, \mathrm{~A} 2572 \mathrm{U}, \Delta 2572$, and $\Delta 2573$; wildtype ribosomes were used for comparison. Because strains expressing ribosomes with the A2572U and C2573A mutations were viable in the absence of wild-type ribosomes, we prepared these mutant ribosomes directly from cells. The mutant ribosomes with lethal mutations $\Delta 2572$ and $\Delta 2573$ could only be expressed in the presence of the wildtype ribosomal operons, and the mutant ribosomes were prepared by affinity chromatography using a streptavidinbinding RNA aptamer. The presence of mutations in $23 \mathrm{~S}$ rRNA was confirmed by primer extension analysis (Leonov et al. 2003).

To test whether the mutations affected the structure of 23S rRNA, we performed chemical probing with the basespecific reagents DMS, kethoxal, and 1-cyclohexyl-3-(2morpholinoethyl)-carbodiimide metho-p-toluene sulfonate (CMCT). Virtually all nucleotides whose reactivity was changed by the mutations were located in the vicinity of the

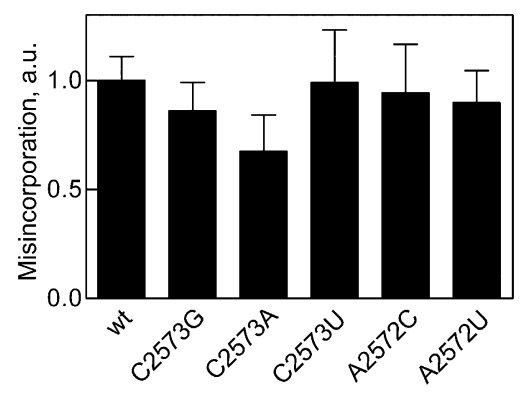

FIGURE 2. Effect of mutations in 23S rRNA on codon reading. Measured is the activity of $\beta$-galactosidase that appears as a result of Gln misincorporation caused by the misreading of a Glu codon. The activities measured with mutant strains are normalized to the activity measured with a strain containing wild-type ribosomes expressed in the same genetic background; "1.0" corresponds to $1.3 \pm 0.1$ Miller units. The activity of the wild-type (wt) ribosomes with the wt lacZ construct (no-error control) was $3980 \pm 700$ Miller units. mutation site (Fig. 3), while the conformation of 23S rRNA regions distant from the mutated position was not affected (data not shown). In most cases, only a few bases changed their reactivities (Fig. 3). These results indicate that the mutations did not cause global distortions of the ribosome structure, but had limited local effects at the accommodation gate.

\section{Initiation and aminoacyl-tRNA accommodation}

The activity of mutant ribosomes in translation initiation was tested by measuring the binding of initiator $f\left[{ }^{3} \mathrm{H}\right]$ Met$\mathrm{tRNA}^{\mathrm{fMet}}$ to the $\mathrm{P}$ site using nitrocellulose filtration. None of the mutations affected the formation of the 70S initiation complex (Fig. 4A), indicating that the activity of the ribosomes in initiation was not impaired by the mutations. The ability to synthesize the dipeptide fMet-Phe upon addition of the ternary complex EF-Tu.GTP. $\left[{ }^{14} \mathrm{C}\right] \mathrm{Phe}-$ tRNA $^{\text {Phe }}$ to the initiation complex was also not affected by the mutations (Fig. 4B), implying that the final level of Phe-tRNA ${ }^{\text {Phe }}$ binding, and hence the proportion of ribosomes with an active A site, was not affected. These observations indicated that the overall activity of the ribosomes was not compromised by the mutations and allowed us to measure the specific effect on the rate of peptide bond formation, which at the present conditions is limited by the rate of the preceding accommodation step (Bieling et al. 2006). The rate of fMet-Phe formation was measured by quench-flow by mixing the initiation complex with the ternary complex and stopping the reaction after the desired times by addition of the quencher. The observed rate of dipeptide formation was approximately the same for wildtype and mutant ribosomes; $k_{\mathrm{app}}=2.3 \pm 0.2 \mathrm{sec}^{-1}(\mathrm{wt})$, $k_{\text {app }}=2.0 \pm 0.2 \mathrm{sec}^{-1}(\Delta 2573), k_{\mathrm{app}}=2.1 \pm 0.2 \mathrm{sec}^{-1}$ $(\mathrm{C} 2573 \mathrm{~A}), k_{\mathrm{app}}=2.8 \pm 0.3 \mathrm{sec}^{-1}(\Delta 2572)$, and $k_{\mathrm{app}}=1.9 \pm$ $0.2 \mathrm{sec}^{-1}$ (A2572U) (Fig. 4C). Thus, none of the mutations of nucleotides 2573 and 2572 in 23S rRNA affected the rate of aa-tRNA accommodation to any appreciable extent. Together with the results of the in vivo assays, these results indicate that the presumed accommodation gate at C2573 is not rate limiting for aa-tRNA accommodation, at least not for Phe-tRNA ${ }^{\text {Phe }}$. It is not excluded, however, that a step different from the one suggested by molecular dynamics simulations limits the rate of accommodation (Sanbonmatsu et al. 2005), or that mutations at the gate cause accommodation to take an alternative pathway. Furthermore, it is possible that the accommodation of aa-tRNAs other than Phe-tRNA $^{\text {Phe }}$ is indeed affected, for instance by the C2573A mutation, which would explain its effect on misreading in vivo.

\section{Peptide release by RF2}

During the termination of protein synthesis, RF1 or RF2 recognizes a stop codon in the $\mathrm{A}$ site and promotes the 


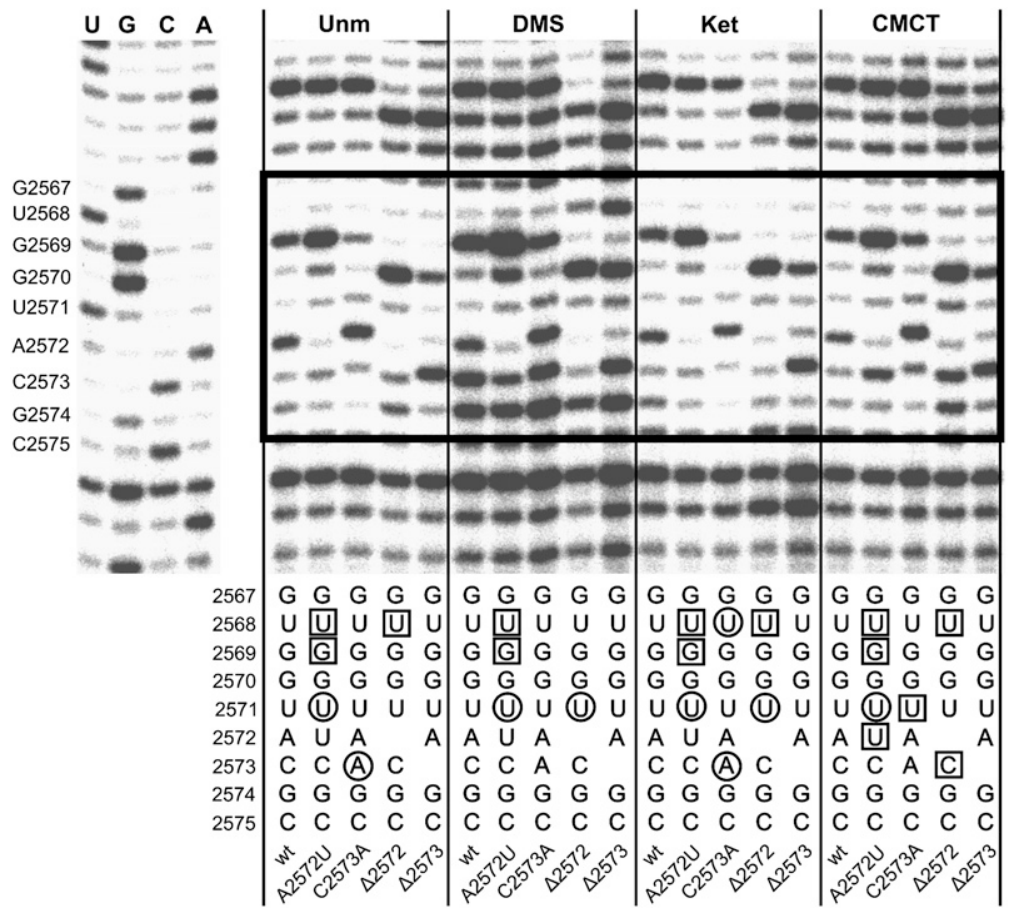

FIGURE 3. Chemical probing of the $23 \mathrm{~S}$ rRNA structure. Fragment of the sequencing gel showing the changes in chemical reactivity in the vicinity of the mutation. Source of the $50 \mathrm{~S}$ subunits is indicated at the bottom. U, G, C, and A denote the respective sequencing lanes. Unm, unmodified rRNA; DMS, after modification with DMS; Ket, after modification with kethoxal; and CMCT, after modification with CMCT. The region in the sequence where changes in chemical reactivity are found is indicated by frame and the effects are summarized in the primary sequence diagram below the gel. Increased chemical reactivity is indicated by squares, decreased reactivity by circles. Shown is sequencing using primers complementary to the 2730-2749 and 2591-2611 regions of 23S rRNA, which cover the region of $23 \mathrm{~S}$ rRNA in which nucleotides forming the accommodation gate are located.

hydrolysis of P-site-bound pept-tRNA in the peptidyl transferase center. To enter the peptidyl transferase center, RFs, like aa-tRNAs, may also have to use the accommodation corridor. This prompted us to study the effect of mutations on the efficiency of RF2-catalyzed peptide release in vitro, using a model system with ribosomes containing fMet-tRNA $^{\text {fMet }}$ bound to an AUG codon in the $\mathrm{P}$ site and a UAA stop codon in the A site (Fig. 4D). The mutation $\mathrm{A} 2572 \mathrm{U}$ decreased the rate of peptide release fourfold $\left(k_{\text {app }}=0.10 \pm 0.01 \mathrm{sec}^{-1}\right)$ compared with the reaction on wild-type ribosomes $\left(k_{\mathrm{app}}=0.46 \pm 0.04 \mathrm{sec}^{-1}\right)$, while the mutations C2573A, $\Delta 2572$ and $\Delta 2573$ only slightly decreased the rate of peptide release $\left(k_{\text {app }}=0.37 \pm\right.$ $0.03 \mathrm{sec}^{-1}, k_{\mathrm{app}}=0.29 \pm 0.03 \mathrm{sec}^{-1}$, and $k_{\mathrm{app}}=0.33 \pm$ $0.05 \mathrm{sec}^{-1}$, respectively). The effect is statistically significant and highly reproducible. It may reflect an impaired accommodation of RF2 in the A site or a slower chemistry step. The interpretation is complicated by the fact that it is not known which of the two steps is rate limiting for RF2dependent peptide release. The reported strong dependence of the reaction rate on the nature of the nucleophile (Shaw and Green 2007) argues against RF2 binding or rearrange- ments being rate limiting for the reaction. This would suggest that the observed rate decrease may reflect the effect on the chemical step of pepttRNA hydrolysis. Because the activity of the peptidyl transferase center in peptide bond formation was not impaired, the inhibition of peptide release by mutations should involve group(s) specific for the hydrolysis reaction, e.g., nucleophile positioning in the active center. On the other hand, if the hydrolysis reaction itself is not affected by the mutations and is rate limiting on the wild-type ribosomes, the true inhibition of RF2 accommodation by the mutation of RF2 accommodation may be larger than that observed upon monitoring the peptide release, because the accommodation step may become rate limiting on mutant ribosomes. In this case, the fourfold decrease in the rate of peptide release can be considered as the lower limit for the effect on the accommodation of RF2. It should be noted that the strongest decrease in the release rate was observed for mutation of nucleotide 2572, which is not participating in the formation of the accommodation gate or of the core of the catalytic center (Korostelev et al. 2008; Weixlbaumer et al. 2008). Nucleotide 2572 may play an important role in the regulation of the gate size or effect the positioning of RF2 in some way. Impairment in RF-dependent termination may also explain why mutations of other residues at the accommodation gate, U2492 and U2555, result in increased stop-codon readthrough in vivo (O'Connor and Dahlberg 1993, 1995)

In summary, the present data indicate that the ribosome is quite robust in dealing with mutations at the accommodation gate, as we have not observed any effect on PhetRNA $^{\text {Phe }}$ accommodation. In comparison, the RF2-dependent peptide release is affected by the mutations, although it is not clear which step of the reaction (the accommodation of the factor in the A site or the chemistry step) is affected. This identifies RFs as potential interesting ligands for molecular dynamics simulations of their accommodation during termination.

\section{MATERIALS AND METHODS}

\section{Buffers}

The following buffers were used: buffer A: $50 \mathrm{mM}$ Tris- $\mathrm{HCl}(\mathrm{pH}$ 7.5), $70 \mathrm{mM} \mathrm{NH}_{4} \mathrm{Cl}, 30 \mathrm{mM} \mathrm{KCl}, 7 \mathrm{mM} \mathrm{MgCl}$; and buffer B: 
A

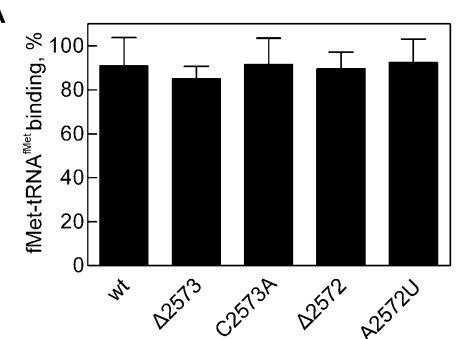

B

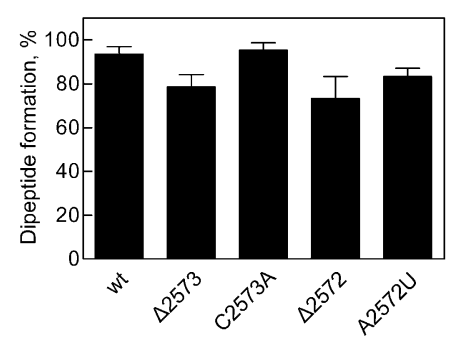

C

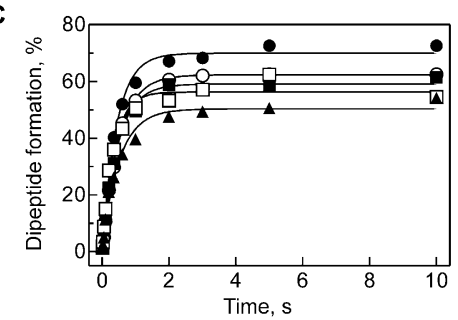

D

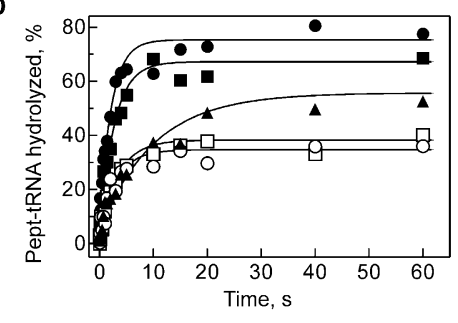

FIGURE 4. Effect of mutations on the elemental steps of translation. (A) fMet-tRNA ${ }^{\text {fMet }}$ binding to the $\mathrm{P}$ site of $70 \mathrm{~S}$ ribosomes in the presence of initiation factors. (B) Peptide bond formation upon addition of EF-Tu•GTP $\bullet\left[{ }^{14} \mathrm{C}\right] \mathrm{Phe}-\mathrm{tRNA}{ }^{\text {Phe }}$ to the $70 \mathrm{~S}$ initiation complexes formed with wild-type (wt) ribosomes, or mutants as indicated. (C) Time courses of dipeptide formation. Symbols: wt ribosomes $(\bullet), \Delta 2573(\bigcirc)$, C2573A (ロ), $\Delta 2572(\square)$, and A2572U $(\boldsymbol{\Delta})$. (D) Kinetics of peptide release. Symbols: wt ribosomes $(\bullet), \Delta 2573(\bigcirc)$, C2573A ( $\mathbf{\square})$, $\Delta 2572(\square)$, and A2572U ( $\mathbf{\Lambda})$.

$20 \mathrm{mM}$ Hepes- $\mathrm{KOH}\left(\mathrm{pH}\right.$ 7.5), $200 \mathrm{mM} \mathrm{NH}_{4} \mathrm{OAc}, 1 \mathrm{mM}$ magnesium acetate, $4 \mathrm{mM} \beta$-mercaptoethanol. All experiments were carried out at $37^{\circ} \mathrm{C}$.

\section{Mutagenesis and ribosome purification}

Mutations were introduced by site-directed mutagenesis into a SphI-BamHI fragment of the E. coli $\mathrm{rrnB}$ operon cloned into M13 mp18 phage (Kunkel 1985). The mutated fragment was cloned into the pLK1192U plasmid containing a streptavidinbinding aptamer ("strep tag") inserted in helix 25 of $23 \mathrm{~S}$ rRNA (Leonov et al. 2003). The plasmid contains the $r r n B$ operon of rDNA under the control of the phage $\lambda \mathrm{P}_{\mathrm{L}}$ promoter. Transformation of the AVS69009 strain (Asai et al. 1999), plasmid substitutions, and testing the purity of mutant rRNA in the cells were carried out as previously described (Sergiev et al. 2000).

Ribosomes and 50S ribosomal subunits were prepared as previously described (Rodnina and Wintermeyer 1995; Milon et al. 2007). To prepare ribosomes with lethal mutations $(\Delta 2572, \Delta 2573$, and UUU2491-3UC), all steps preceding the zonal centrifugation were carried out as previously described (Rodnina and Wintermeyer 1995), followed by the isolation of mutant 50 S subunits by strep-tag affinity chromatography (Leonov et al. 2003).

\section{In vivo assays}

Doubling times were measured by monitoring $\mathrm{A}_{600}$ in LuriaBertani medium at $37^{\circ} \mathrm{C}$, using three independent clones to monitor the growth rate of each strain. Doubling times were calculated by a least-squares linear approximation of the logarithms of the optical density of the cultures in their log phase. For translation fidelity assays, the cells were harvested at the same stage of growth, namely, the mid-log phase. Translational fidelity was measured using a set of $L a c Z$ reporter strains (pSG or $\mathrm{f}^{\prime} \mathrm{CSH}$ ) (O'Connor and Dahlberg 1993; Sergiev et al. 2005). E. coli strain MC140 carrying one of the reporter plasmids was transformed by one of the plasmids carrying a wild-type or mutant $23 \mathrm{~S}$ rRNA gene. The activity of $\beta$-galactosidase was determined from at least three independent experiments as previously described (O'Connor and Dahlberg 1993).

\section{Chemical probing}

DMS, kethoxal, and CMCT modifications were carried out following Stern et al. (1988), with the exception that modifications were done for $10 \mathrm{~min}$ at $37^{\circ} \mathrm{C}$. Ribosomal RNA was purified by repeated phenol extractions, and modified sites were determined by primer extension with AMV reverse transcriptase.

\section{Biochemical methods}

EF-Tu, initiation factors, $\mathrm{f}\left[{ }^{3} \mathrm{H}\right]$ Met$\mathrm{tRNA}^{\mathrm{fMet}}$, and $\left[{ }^{14} \mathrm{C}\right] \mathrm{Phe}-\mathrm{tRNA}{ }^{\text {Phe }}$ from E. coli were prepared as previously described (Rodnina et al. 1994; Rodnina and Wintermeyer 1995; Rodnina et al. 1999). $\mathrm{f}\left[{ }^{3} \mathrm{H}\right] \mathrm{Met}-\mathrm{tRNA}{ }^{\mathrm{fMet}}$ and $\left[{ }^{14} \mathrm{C}\right] \mathrm{Phe}$-tRNA ${ }^{\text {Phe }}$ were purified to homogeneity by HPLC (Milon et al. 2007). mRNA-1 coding for fMet-Phe (5'-GGCAAGGAGGUAAAUAAU GUUCACGAUU-3' [coding sequence underlined]) and mRNA-2 coding for fMet-Stop (5'-GGCAAGGAGGUAAAUAAUGUAA ACGAUU-3') were purchased from Dharmacon or Curevac. Initiation or pretermination complexes were formed by incubation of wild-type $30 \mathrm{~S}$ subunits $(1 \mu \mathrm{M})$ and mutant $50 \mathrm{~S}$ subunits $(1 \mu \mathrm{M})$ with mRNA-1 or mRNA-2 $(1.5 \mu \mathrm{M})$ as appropriate, $\left.\mathrm{f}^{3} \mathrm{H}\right] \mathrm{Met}^{-\mathrm{HNNA}^{\mathrm{fMet}}}(1.5 \mu \mathrm{M})$, IF1, IF2, and IF3 (1.5 $\mu \mathrm{M}$ each), DTT $(1 \mathrm{mM})$, and GTP $(1 \mathrm{mM})$ in buffer $\mathrm{A}$ at $37^{\circ} \mathrm{C}$ for $45 \mathrm{~min}$. The amount of $\left.\mathrm{f}^{3} \mathrm{H}\right]$ Met-tRNA ${ }^{\mathrm{fMet}}$ bound to the $\mathrm{P}$ site was determined by nitrocellulose filtration. The ternary complex, EFTu•GTP• $\left[{ }^{14} \mathrm{C}\right]$ Phe-tRNA ${ }^{\text {Phe }}$, was prepared by incubating EF-Tu $(3 \mu \mathrm{M})$ with GTP $(1 \mathrm{mM})$, phosphoenol pyruvate $(3 \mathrm{mM})$, and pyruvate kinase $(0.1 \mathrm{mg} / \mathrm{mL})$ in buffer $\mathrm{A}$ at $37^{\circ} \mathrm{C}$ for $15 \mathrm{~min}$, followed by the addition of $\left[{ }^{14} \mathrm{C}\right]$ Phe-tRNA ${ }^{\text {Phe }}(2 \mu \mathrm{M})$. To measure dipeptide formation, the initiation complex $(0.4 \mu \mathrm{M})$ was mixed with a ternary complex $(0.6 \mu \mathrm{M})$ and incubated for 2 $\min$ at $37^{\circ} \mathrm{C}$. The reaction was stopped with $0.5 \mathrm{M} \mathrm{KOH}$, incubated for $30 \mathrm{~min}$ at $37^{\circ} \mathrm{C}$, neutralized, and the dipeptide formed was analyzed by RP-HPLC (Katunin et al. 2002).

\section{Rapid kinetics experiments}

Quench-flow assays were performed at $37^{\circ} \mathrm{C}$ in a KinTek RQF-5 apparatus. To measure the time courses of peptide bond formation, the initiation complex $(0.25 \mu \mathrm{M})$ was rapidly mixed with a ternary complex $(0.375 \mu \mathrm{M})$. After different incubation times, reactions were stopped with $\mathrm{KOH}(0.5 \mathrm{M})$ and analyzed as described above. To measure the rate of fMet release, pretermination complexes $(0.2 \mu \mathrm{M})$ were mixed with RF2 $(0.4 \mu \mathrm{M})$. Reactions were stopped with $6 \%$ TCA, f[ $\left.{ }^{3} \mathrm{H}\right] \mathrm{Met}_{\text {-tRNA }}{ }^{\mathrm{fMet}}$ and 
deacylated tRNA ${ }^{\text {fMet }}$ were precipitated by addition of three volumes of ethanol, and the amount of liberated $\mathrm{f}\left[{ }^{3} \mathrm{H}\right] \mathrm{Met}$ was determined by measuring the radioactivity in the supernatant.

\section{ACKNOWLEDGMENTS}

We thank Wolfgang Wintermeyer for valuable comments on the manuscript; and Carmen Schillings, Astrid Böhm, and Simone Möbitz for expert technical assistance. This work was supported by INTAS fellowship grant for Young Scientists No. 05-109-4696, Russian Foundation for Basic Research Grant Nos. 08-04-01212 and 08-04-00974, Human Frontier Science Program Grant No. RGY0088/2008, U.S. Civilian Research and Development Foundation Grant No. RUB1-33006-MO-08, Howard Hughes Medical Institute Grant No. 55005605, the Deutsche Forschungsgemeinschaft, and the International Bureau of the Federal Ministry of Education and Research, Germany.

Received March 19, 2010; accepted June 16, 2010.

\section{REFERENCES}

Asai T, Zaporojets D, Squires C, Squires CL. 1999. An Escherichia coli strain with all chromosomal rRNA operons inactivated: Complete exchange of rRNA genes between bacteria. Proc Natl Acad Sci 96: 1971-1976.

Beringer M, Bruell C, Xiong L, Pfister P, Bieling P, Katunin VI, Mankin AS, Bottger EC, Rodnina MV. 2005. Essential mechanisms in the catalysis of peptide bond formation on the ribosome. J Biol Chem 280: 36065-36072.

Bieling P, Beringer M, Adio S, Rodnina MV. 2006. Peptide bond formation does not involve acid-base catalysis by ribosomal residues. Nat Struct Mol Biol 13: 423-428.

Borovinskaya MA, Pai RD, Zhang W, Schuwirth BS, Holton JM, Hirokawa G, Kaji H, Kaji A, Cate JH. 2007. Structural basis for aminoglycoside inhibition of bacterial ribosome recycling. Nat Struct Mol Biol 14: 727-732.

Chan YL, Dresios J, Wool IG. 2006. A pathway for the transmission of allosteric signals in the ribosome through a network of RNA tertiary interactions. J Mol Biol 355: 1014-1025.

Cupples CG, Miller JH. 1989. A set of lacZ mutations in Escherichia coli that allow rapid detection of each of the six base substitutions. Proc Natl Acad Sci 86: 5345-5349.

Gregory ST, Dahlberg AE. 1999. Erythromycin resistance mutations in ribosomal proteins L22 and L4 perturb the higher order structure of 23 S ribosomal RNA. J Mol Biol 289: 827-834.

Katunin VI, Muth GW, Strobel SA, Wintermeyer W, Rodnina MV. 2002. Important contribution to catalysis of peptide bond formation by a single ionizing group within the ribosome. Mol Cell 10: 339-346.
Korostelev A, Asahara H, Lancaster L, Laurberg M, Hirschi A, Zhu J, Trakhanov S, Scott WG, Noller HF. 2008. Crystal structure of a translation termination complex formed with release factor RF2. Proc Natl Acad Sci 105: 19684-19689.

Kunkel TA. 1985. Rapid and efficient site-specific mutagenesis without phenotypic selection. Proc Natl Acad Sci 82: 488-492.

Leonov AA, Sergiev PV, Bogdanov AA, Brimacombe R, Dontsova OA. 2003. Affinity purification of ribosomes with a lethal G2655C mutation in $23 \mathrm{~S}$ rRNA that affects the translocation. J Biol Chem 278: $25664-25670$.

Meskauskas A, Dinman JD. 2007. Ribosomal protein L3: Gatekeeper to the A site. Mol Cell 25: 877-888.

Milon P, Konevega AL, Peske F, Fabbretti A, Gualerzi CO, Rodnina MV. 2007. Transient kinetics, fluorescence, and FRET in studies of initiation of translation in bacteria. Methods Enzymol 430: 1-30.

O'Connor M, Dahlberg AE. 1993. Mutations at U2555, a tRNAprotected base in $23 \mathrm{~S}$ rRNA, affect translational fidelity. Proc Natl Acad Sci 90: 9214-9218.

O'Connor M, Dahlberg AE. 1995. The involvement of two distinct regions of $23 \mathrm{~S}$ ribosomal RNA in tRNA selection. J Mol Biol 254: 838-847.

Rodnina MV, Wintermeyer W. 1995. GTP consumption of elongation factor Tu during translation of heteropolymeric mRNAs. Proc Natl Acad Sci 92: 1945-1949.

Rodnina MV, Fricke R, Wintermeyer W. 1994. Transient conformational states of aminoacyl-tRNA during ribosome binding catalyzed by elongation factor Tu. Biochemistry 33: 12267-12275.

Rodnina MV, Savelsbergh A, Matassova NB, Katunin VI, Semenkov YP, Wintermeyer W. 1999. Thiostrepton inhibits the turnover but not the GTPase of elongation factor G on the ribosome. Proc Natl Acad Sci 96: 9586-9590.

Sanbonmatsu KY, Joseph S, Tung CS. 2005. Simulating movement of tRNA into the ribosome during decoding. Proc Natl Acad Sci 102: 15854-15859.

Sergiev PV, Bogdanov AA, Dahlberg AE, Dontsova O. 2000. Mutations at position A960 of E. coli $23 \mathrm{~S}$ ribosomal RNA influence the structure of $5 \mathrm{~S}$ ribosomal RNA and the peptidyltransferase region of 23 S ribosomal RNA. J Mol Biol 299: 379-389.

Sergiev PV, Kiparisov SV, Burakovsky DE, Lesnyak DV, Leonov AA, Bogdanov AA, Dontsova OA. 2005. The conserved A-site finger of the 23S rRNA: Just one of the intersubunit bridges or a part of the allosteric communication pathway? J Mol Biol 353: 116-123.

Shaw JJ, Green R. 2007. Two distinct components of release factor function uncovered by nucleophile partitioning analysis. Mol Cell 28: $458-467$.

Stern S, Moazed D, Noller HF. 1988. Structural analysis of RNA using chemical and enzymatic probing monitored by primer extension. Methods Enzymol 164: 481-489.

Weixlbaumer A, Jin H, Neubauer C, Voorhees RM, Petry S, Kelley AC, Ramakrishnan V. 2008. Insights into translational termination from the structure of RF2 bound to the ribosome. Science 322: 953-956.

Zamir A, Miskin R, Vogel Z, Elson D. 1974. The inactivation and reactivation of Escherichia coli ribosomes. Methods Enzymol 30: 406-426. 

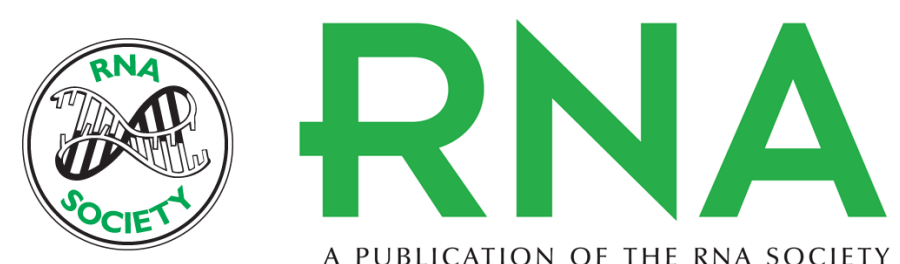

A PUBLICATION OF THE RNA SOCIETY

\section{Mutations at the accommodation gate of the ribosome impair RF2-dependent translation termination}

Dmitry E. Burakovsky, Petr V. Sergiev, Maria A. Steblyanko, et al.

RNA 2010 16: 1848-1853 originally published online July 28, 2010

Access the most recent version at doi:10.1261/rna.2185710

$\begin{array}{ll}\text { References } & \begin{array}{l}\text { This article cites } 25 \text { articles, } 11 \text { of which can be accessed free at: } \\ \text { http://rnajournal.cshlp.org/content/16/9/1848.full.html\#ref-list-1 }\end{array}\end{array}$

License

Email Alerting Receive free email alerts when new articles cite this article - sign up in the box at the Service top right corner of the article or click here. 